\title{
ORDEN PÚBLICO DEL MERCOSUR: UN INTROITO
}

\author{
Rafael Nascimento Reis ${ }^{\star}$
}

\section{Resumen}

El presente artículo pretende instigar el debate en el campo del derecho internacional privado de la integración sobre un tema todavía inicial: la existencia de un orden público regional. El texto busca transcurrir el histórico, las características, los distintos niveles y operatividad del orden público, sobretodo, a partir de las bases doctrinarias del gran maestro Dolinger. Bajo la perspectiva del derecho de la integración presentamos las inquietudes sobre la existencia y distinción de un orden público mercosureño en contraposición a un orden público nacional. Al final, aportamos la teoría hermenéutica del profesor Friedrich Müller ya consolidada en el ámbito del derecho constitucional y la trasladamos para nuestro tema en debate, llegando a algunas conclusiones sobre la convivencia mutua entre los distintos órdenes públicos nacionales y el orden público regional.

Palabras-clave: Orden público. Integración. MERCOSUR. Hermenéutica.

\section{Introducción}

Antes de todo, es necesario decir los motivos que inspiraron ese autor a escribir ese pequeño texto, sencillo en su contenido, pero pretencioso en sus objetivos. Primero, los años ya recorridos en investigaciones sobre el Mercosur. Segundo, la pasión por el derecho constitucional, sobretodo, la hermenéutica constitucional. Tercero, la idea de profundizar en grandes temas del derecho internacional privado, como el orden público. Cuarto, aliar todas esas materias en un artículo que intenta introducir el tema para una futura tesis. Esta puesto el desafío.

El objetivo de esa producción científica es intentar hacer dialogar un gran tema del derecho internacional privado, el orden público, con la hermenéutica jurídica contemporánea, en ese caso, trayendo aportes desde la hermenéutica constitucional alemán.

Ese intento revela de suma importancia, ya que en una nueva orden mundial multipolar, donde la aplicación del derecho extranjero es un hecho cotidiano en las Cortes de varios países en el mundo, el orden público demuestra ser un refugio para los Estados cuando la diversidad cultural y "lo distinto" no merece entrar por las puertas del "Estado nación".

\footnotetext{
Secretario de Relaciones Institucionales y Comunicación Social del Parlamento del Mercosur. Maestrando en Relaciones Internacionales de la Universidad de la República del Uruguay. Graduado en Derecho por el Centro Universitario de Brasília - UniCEUB.
} 
Pero, todavía hay que hablar en "Estado-nación” en los días de hoy? Hay solamente el orden público internacional de los Estados? O hay diferentes instancias de orden público internacional?

En un mundo donde cada vez los países se agrupan en sistemas de integración regionales y la cooperación internacional aflorase, parece surgir una nueva instancia del orden público internacional, un orden público que represente lo límite de los derechos protegidos. Quizás un orden público internacional más amplio que aquél comprendido por cada Estado. Un orden público regional, comunitario, en nuestro caso, un orden público fruto de la integración de cuatro países: El Orden Público del Mercosur.

\section{Orden público}

\subsection{Noción del orden público en el derecho internacional privado}

Es importante destacar que, tradicionalmente, durante mucho tiempo se entendió el orden público, sobretodo en su faceta interna, como un elemento limitador ${ }^{1}$ de la autonomía de la voluntad de las partes. ${ }^{2}$

Sobresale la regla de los romanos, en que decía privatorum conventio juri publico non derrogat o jus publicum privatorum pactis mutari non potest, apartando la voluntad de las partes delante del derecho público y algunas normas de derecho privado, considerados principios jurídicos inderogables.

Según Wengler ${ }^{3}$, el principio del orden público es uno de los más importantes del derecho internacional privado, en el momento en que lo mismo impide la aplicación de las leyes extranjeras el reconocimiento de actos realizados en el extranjero, bien como la ejecución de sentencias falladas por tribunales extranjeros.

Para Goldschmidt, el concepto del orden público supone dos circunstancias " 1 ” una diversidad ideológica dentro de la comunidad de aquellos pueblos que aplican mutuamente sus respectivos Derechos; $2^{\circ}$ el reconocimiento de una obligación jurídica de aplicar Derecho extranjero". 4

\footnotetext{
${ }^{1}$ Según Werner Goldschmidt, "si las disposiciones del orden público internacional son sustitutivas (de las extranjeras), su aplicación es apriorística; si, al contrario, tales disposiciones son limitativas (de las extranjeras), su aplicación es a posteriori." GOLDSCHMIDT, Werner. Derecho internacional privado. 9 ed. Buenos Aires: Depalma, 2002. p. 151.

${ }^{2}$ DOLINGER, Jacob. direito Internacional privado: parte geral. 7. ed. Rio de Janeiro: Renovar, 2003. p. 391.

${ }^{3}$ Dolinger apud WENGLER, William. Curso de la Academia Internacional de la Haya. Recueil des Cours, [S.1.], v. 104, t. 3, 1961: "Obviously, the ordre public clause may itself be in conflicto with the principle of international uniformity of decisions, but it is an esencial feature of the clause that it is stronger tan any other general principle of prívate international law".

${ }^{4}$ GOLDSCHMIDT, Werner. Derecho internacional privado. 9 ed. Buenos Aires: Depalma, 2002. p. 147.
} 
Trayendo otros aportes, Dolinger enfatiza que el principio del orden público posee naturaleza filosófica, moral, relativa, alterable, indefinible. Continúa afirmando que el principio es el reflejo de la filosofía socio-político-jurídica de toda la legislación, que representa la moral básica de una nación y que protege las necesidades económicas del Estado. ${ }^{5}$

Vale destacar que en el fenómeno social tiene un relevancia fundamental cuando estamos analizando el orden publico, ya que la Justicia deberá considerar los aspectos de mentalidad y sentimiento de la sociedad sobre el tema en debate.

La Corte Internacional de Justicia, en el juzgamiento del caso Boll, el juez Sir Hersch Lauterpacht entendió y aclaró la distinción entre el orden público, cuando hablamos de los temas de derecho propriamente dicho, y el orden público cuando se trata más genéricamente del mismo o sea los conceptos fundamentales de la ley, de la decencia y de la moralidad. ${ }^{6}$

Es posible encontrar, por ejemplo, en el Código de Bustamente, otra distinción del orden publico, donde lo mismo, en su artigo tercero, clasifica en leyes y reglas de orden publico interno, de orden publico internacional y voluntarias, o de orden privada.

\section{a. Histórico}

El origen del principio en la disciplina del derecho internacional privado parece encontrarse en Bártolo, en que distinguía los estatutos odiosos de los estatutos favorables. ${ }^{7}$

Según Goldschmidt, fue en 1849, con la publicación del octavo volumen de la obra Sistema del derecho romano actual, de Savigny, que se reúnen por la primera vez las dos circunstancias básicas del orden público. Vale resaltar que Savigny no habla de “orden público", en eses términos, y si de "leyes rigurosamente prohibitivas". Para el autor alemán, no se debe aplicar Derecho extranjero, si conculca las primeras o contiene una institución desconocida. ${ }^{8}$

Story, que fue juez de la Suprema Corte norte-americana, publicó libro en 1834, aclarando el tema del principio del orden público, vemos:

Nación alguna puede ser justamente requerida á ceder sus conveniencias políticas e instituciones fundamentales a favor de las de otra nación. Mucho menos puede nación alguna ser requerida a sacrificar sus

${ }^{5}$ DOLINGER, Jacob. direito Internacional privado: parte geral. 7. ed. Rio de Janeiro: Renovar, 2003. p. 392.

${ }^{6}$ DOLINGER citando la Corte Internacional de Justicia - Recueil des Arrêts, Avis Consultatifs et Ordonances, 1958. p. 90.

${ }^{7}$ Para Goldschmidt, “Los llamados 'privilegios odiosos' no tienen parentesco con el orden público, puesto que la inaplicación de los primeros (por ejemplo, un estatuto que incapacite a las mujeres de heredar, a favor de los varones) derogaba Derecho particular en sí inaplicable - el de las ciudades - a favor del Derecho común en sí aplicable - el romano -, mientras que el orden público deroga el Derecho aplicable en sí aplicable - el extranjero - a favor de un Derecho particular en sí inaplicable - el proprio. GOLDSCHMIDT, Werner. Derecho internacional privado. 9 ed. Buenos Aires: Depalma, 2002. p. 147.

${ }^{8}$ Ibidem, p. 148. 
intereses a favor de otra, o a practicar doctrinas que, en un concepto moral o político sean incompatibles con su seguridad o felicidad, o con su conciencia de la justicia y del deber.

En las interminables diversidades de la humana jurisprudencia, muchas leyes tienen que existir en un país, que son el resultado de circunstancias locales o accidentales, y que son completamente ineptas para ser incorporadas en las instituciones y hábitos de otro. No pocas leyes, bastante bien adaptadas a las naciones gentiles serian totalmente repugnantes a los sentimientos, así como a la justicia de las que abrazan el Cristianismo. Una nación gentil bien puede justificar la poligamia, o el incesto, los contratos de turpidud moral, o los ejercicios de crueldad despótica a las personas, que serian repugnantes a los primeros principios del deber cristiano. Las leyes de una nación pueden fundarse en un estrecho egoísmo, exclusivamente destinado a promover su política, o el interés personal o propietario de sus súbditos con perjuicio y aun con ruina de los súbditos de todos los otros países...

En estos, como en muchos otros casos que pueden fácilmente proponerse sin hacer suposiciones extravagantes, habría extrema dificultad en decir que otras naciones estaban obligadas a hacer efectivas leyes, instituciones, o costumbres de esa nación, que fuesen subversivas de su moral, su justicia, su interés, o su política. ${ }^{9}$

En Francia, el principio del orden público se encuentra deducido en el art. $3^{\circ}$, inciso I, del Código Civil, "Las leyes de policía y de seguridad obligan todos los que habitan el territorio". La Corte de Casación francesa ya delimitó el concepto popular de orden público en un fallo de 1944, veamos: "la définition de l'ordre public national dépendant dans une large mesure de l'opinion qui prévant à chaque momento en France [...]"'ıto

\section{b. Características da Orden Público}

Según Dolinger, el orden público posee algunas características, que serian tres, relatividad/instabilidad, contemporaneidad y factor exógeno.

El principio del orden público es relativo, inestable, ya que varia en el tiempo y el espacio, o sea, el principio se altera de un determinada época para otra, bien como, de un región para otra.

De la misma forma, el principio del orden público debe ser aplicado según el enfoque de la contemporaneidad, o sea, la interpretación del orden publico debe ser aplicado según la época en que se va juzgar la cuestión y no la época de la ocurrencia de los hechos del caso.

Así, la evolución del orden público en un determinado caso, apuntando para una mayor liberalidad, permite la aplicación del derecho extranjero a todos los actos en que en el pasado, la lex fori rechazaba ese mismo derecho. Por ejemplo, en Francia, la Corte de Casación, en un fallo de 1976, dejó bien claro la característica de la actualidad del principio de orden público:

${ }_{9}^{9}$ DOLINGER citando STORY, Joseph. Comentarios sobre el conflicto de las leyes, [S.1.], v. 1, n. 25, p. 32-33.

${ }^{10}$ DOLINGER hace referencia a ese fallo de la Corte de Casación de Francia que puede ser encontrado en Repertoire Lapradelle et Niboyet, $\mathrm{n}^{\circ} 451$. 
La compatibilidad de una investigación de paternidad adulterina con el orden público internacional como concebida en la Francia, debe ser examinada de acuerdo con la situación en el día en que el juez francés va a decidir la homologación de la sentencia extranjera y no de acuerdo con la situación en el día en que fue proferida la decisión extranjera. ${ }^{11}$

Puede ser también que ocurra el inverso, o sea, la contemporaneidad actué de manera en que un determinado acto era admlitido en el País A a la época en que ocurrió el hecho, pero más tarde, el mismo hecho ofende el orden público de ese país, impidiendo la homologación por el Judiciario. ${ }^{12}$

La última característica, según el jurista Dolinger, es el factor exógeno del principio del orden público. Durante el siglo XIX, la doctrina distinguía las leyes internas como obligatorias y otras como supletivas, incluyendo en aquella primera, las normas de orden público, no admitiendo sustitución por normas extranjeras. Esa distinción fue plasmada para el Código Civil italiano de 1865, que en su artículo 12 decía: "Las leyes, actos y sentencias de países extranjeros, bien como las convenciones particulares no podrán, en caso algún, derogar las leyes prohibitivas del reino que conciernen a las personas, cosas y a los actos, ni leyes referentes de cualquier modo a el orden público y al bueno costumbre".

Empero, Etiene Bartin ${ }^{13}$ no entendía de la misma manera. Para este doctrinador, esa clasificación de las leyes es factible de erro, ya que la misma ley podrá, algunas veces, caracterizarse como de orden público y en otras oportunidades no actuar de la misma forma. Dolinger comentando Bartin, escribió:

Determinada norma jurídica do foro será aplicada em substituição à norma do país A, indicada como competente por uma regra de conexão, por ser a lei deste país A chocante à ordem pública do foro, mas não será aplicada a mesma lei do foro quando invocada norma correspondente do país B, também diversa da lei local, mas que não lhe seja chocante. Assim, a norma do foro, na primeira hipótese foi aplicada em substituição à norma estrangeira competente, por ser esta atentatória à ordem pública, enquanto que na segunda hipótese não foi aplicada a norma do foro, permitindo-se a aplicação da lei do país B, por nada ter de atentatório apesar de conter norma diferente. ${ }^{14}$

El doctrinador brasileño, para mejor explicar la distinción, presenta un ejemplo que se pasaba en Brasil, antes del nuevo Código Civil de 2002, veamos:

No Brasil, o Código Civil estabelecia a capacidade jurídica aos 21 anos de idade, alterada para 18 anos pelo Novo Código Civil. Mesmo no regime do código de 1916, os domiciliados na França, onde a regra determina a capacidade aos 18

${ }^{11}$ DOLINGER apud CLUNET, 1977, p. 504, e na REVUE, 1977, p. 749.

${ }^{12}$ Haciendo referencia a la actualidad del orden público, Goldschmidt dijo "Los principios de orden público internacional pueden cambiar en el trascurso del tiempo. Pero precisamente por su manera de ser ellos son necesariamente retroactivos; he aquí lo que se llama la 'actualidad del orden público'. GOLDSCHMIDT, Werner. Derecho internacional privado. 9 ed. Buenos Aires: Depalma, 2002. p. 159.

${ }^{13}$ ETIENNE BARTIN, Principles de droit international privé. [S.1., s.n.]. p. 259.

${ }^{14}$ DOLINGER, Jacob. direito Internacional privado: parte geral. 7. ed. Rio de Janeiro: Renovar, 2003. p. 401. 
anos, tinham este status reconhecido no Brasil, por força do artigo $7^{\circ}$ da Lei de Introdução. Já a legislação de qualquer outro país que determinar a maioridade aos 12 anos não será aplicável no Brasil, mesmo para os domiciliados naquela jurisdição. Por quê? Não porque a norma brasileira de maioridade aos 21 seja de ordem pública. Em absoluto. Se assim fosse, não poderíamos aplicar a lei francesa. É porque à ordem pública brasileira, que não está inscrita em nenhuma lei específica, mas está ínsita na mentalidade, no espírito, na filosofia brasileiras, choca reconhecer capacidade jurídica a uma criança de 12 anos de idade mas considera perfeitamente aceitável reconhecer capacidade jurídica a um jovem de 18 anos de idade. ${ }^{15}$

Para concluir, Dolinger nos ofrece una noción de orden público, que a nosotros parece ser el más apropiado, "las leyes no son de orden publico, esto es, el orden público no es un factor inmanente a la norma jurídica. Esta puede ser imperativa, prohibitiva, tener carácter obligatorio, jus cogens, pero la característica del orden público es exógena."16

Goldschmidt explana bien ese tema, una vez que entiende el orden público como conjunto de principios. Veamos: "Siendo el orden público un conjunto de principios, no es posible partir de ellos, por carecer de fuerza operativa. Hay que empezar con la búsqueda del Derecho aplicable (aplicación de nuestro DIPr), luego urge enterarse de la solución del caso en virtud del Derecho extranjero aplicable (imitación provisional del Derecho extranjero), y sólo después, en otras palabras, a posteriori, será posible controlar la compatibilidad de aquélla con los principios inalienables". ${ }^{17}$

\section{c. Los distintos niveles del Orden Público ${ }^{18}$}

Los distintos niveles del Orden público pasan por el tema de la famosa dicotomía atribuida al orden público, sugerida por Paolo Esperson (Italia) y por Charles Brocher ${ }^{19}$ (Francia) - siglo XIX -, donde aquella tenería dos facetas, una en el plano interno y otra manifestada en el derecho internacional privado.

${ }^{15}$ DOLINGER, Jacob. direito Internacional privado: parte geral. 7. ed. Rio de Janeiro: Renovar, 2003. p. 401.

${ }^{16}$ Ibidem, p. 401-402.

${ }^{17}$ GOLDSCHMIDT, Werner. Derecho internacional privado. 9 ed. Buenos Aires: Depalma, 2002. p. 152.

${ }^{18}$ En ese ítem, no hacemos referencia a la distinción mencionada por el doctrinador Goldschmidt acerca de la estructura del orden público. Goldschmidt, en su libro Derecho Internacional Privado, presenta las dos posiciones distintas sobre la estructura: los defensores del orden público como conjunto de disposiciones y los defensores del orden público como conjunto de principios. No presentamos esa discusión en el presente trabajo, como ya partimos de la idea de que el orden público es un conjunto de principios, con aplicabilidad a posteriori. Para refuerzo de nuestra posición, traemos lo que se acordó en el Séptimo Congreso del "Instituto Hispano-Luso-Americano de Derecho Internacional, Buenos Aires, agosto de 1969: "Considerando que la noción del orden público implica la previa identificación de la ley extranjera llamada a regir un caso concreto, y excluye su aplicación si tal ley contradice los principios fundamentales del ordenamiento jurídico nacional, el VII ${ }^{\circ}$ Congreso del Instituto Hispano-Luso-Americano de Derecho Internacional declara como principio de base que un Derecho extranjero declarado aplicable deja de serlo si la solución del caso concreto pudiera infringir los principios fundamentales que rigen la solución en el ordenamiento jurídico nacional." GOLDSCHMIDT, op. cit., p. 157.

${ }^{19}$ Sobre Brocher, Goldschmidt acrecienta diciendo que lo mismo también era defensor del orden público como conjunto de disposiciones, al contrario del proprio Goldschmidt y do presente autor de ese trabajo. 
Empero, Pillet critica esa dicotomía, refutando la doble faceta del orden público, diciendo que en verdad, lo que pasa es que el orden público tiene efectos distintos cuando de su aplicación, pero la finalidad es única, que sea, proteger la seguridad y la conservación del Estado.

En la doctrina brasileña, tenemos dos grandes autores de derecho internacional privado que representan bien esa crítica. Luiz Araújo Corrêa de Brito afirma que el principio del orden público es siempre nacional, el que puede ocurrir es la duplicidad de sus efectos, o sea, único con relación a la fuente generadora y dual en relación a los efectos de su aplicación o incidencia.

El grande jusprivatista internacional brasileño, Amilcar de Castro, enseña que las amenazas al orden público puede venir de dos direcciones distintas, por leyes/actos/sentencias originadas en la jurisdicción nacional o en el extranjero, resume:

A ordem social ou ordem pública é uma e indivisível, mas como pode ser agredida de dois modos, por ataques provenientes de situações diversas, é sempre defendida por dois modos. A terminologia empregada por Brocher deu lugar a supor-se haver duas espécies de ordem pública, quando isto é inconcebível. Diferença se encontra nos meios de defesa da ordem pública, não nesta em si mesma, que não pode deixar de ser uma só, sempre original, ímpar e indivisível. ${ }^{20}$

Dolinger defiende tres niveles distintos de aplicación del principio del orden público, resaltando que sus distinciones no son cuanto a la naturaleza del principio y si, a respecto de su incidencia cuando de su aplicación.

El primero nivel dice respecto cuando el orden público es aplicado en el plano interno, garantizando el imperio de algunas reglas jurídicas frente a la derogación pretendida por las partes. Son ejemplos, las leyes de protección a los niños y adolescentes, a los incapaces, a la familia, etc. ${ }^{21}$

El segundo nivel del principio del orden público ocurre cuando este impide la aplicación del derecho extranjero indicada por la regla de conexión del derecho internacional privado. Explica el autor que ni toda ley local que no puede ser derogada por las partes en el plano interno (primero nivel de aplicación) no podrá ser sustituida por una ley extranjera, cuando estamos hablando del segundo nivel de aplicación. En la verdad eso depende del caso concreto, el autor brasileño presenta un ejemplo donde un adolescente de 16 años, según la legislación brasileña, es relativamente incapaz, no pudendo, en el plano interno, lo mismo renunciar a esa condición por su propia voluntad, es una cuestión de orden público. Sin embargo, si en el plano del derecho internacional privado, si la ley extranjera no considera

${ }^{20}$ Amilcar de Castro apud DOLINGER, Jacob. direito Internacional privado: parte geral. 7. ed. Rio de Janeiro: Renovar, 2003. p. 265.

${ }^{21}$ DOLINGER, op. cit., p. 404. 
el mismo adolescente de 16 años como incapaz, es posible el juez brasileño aceptar ese derecho extranjero, sin cualquier ofensa a la orden público.

El problema está cuando la ley extranjera posee límites mucho distintos del nuestro, como una ley que considera el chico de 12 años como capaz, eso afronta directamente el orden público. Pero porque? Una respuesta sencilla podría ser porque el orden público brasileño, o sea, la mentalidad media de la sociedad tupiniquim entiende que el menor de 12 año no tiene, aún, la capacidad de ser responsabilizado por sus actos, debiendo tener la protección del Estado. Es una cuestión como decía Wangler, de naturaleza filosófica, relativa y moral de una sociedad en un determinado tiempo y espacio.

El tercero nivel propuesto por Dolinger es a respecto de la intervención del orden público cuando del reconocimiento de los derechos adquiridos en el exterior. El ejemplo más claro de ese nivel, es de la segunda esposa del casamiento poligámico que requiere alimentos en un país cuyo el sistema jurídico prohíbe ese tipo de matrimonio. Como denegar alimentos a esa esposa, una vez que ella contrajo ese matrimonio en el exterior, donde era permitido lo mismo. Bueno, la aplicación del tercero nivel ocurre en ese tipo de situación, mismo que el sistema jurídico del país donde se solicita los alimentos no permite el matrimonio poligámico, se reconoce la legitimidad de la segunda esposa y su pretensión de alimentos. ${ }^{22}$

\section{d. Sustitución de la Lex Causae por la Lex Fori}

Según Dolinger ${ }^{23}$, la operatividad del orden público implica en la sustitución de la lex causae por la lex fori, pudiendo tener dos efectos:

- un negativo, cuando la ley local prohíbe aquello que la ley extranjera permite (ejemplos: divorcio, poligamia, etc). De esa forma no admite la aplicación de la ley extranjera permisiva;

- un positivo, cuando la ley extranjera prohíbe aquello que la ley local permite (ejemplos: matrimonios inter-raciales, de clérigos, divorcio, etc). En ese caso, el orden público local exige que se conceda el derecho o la facultad prohibida o desconocida por ley personal.

\section{El orden público del Mercosur?}

Empezamos con esa frase:

En un sistema de integración, en realidad lo que existe es un orden público regional que precisamente hace imperiosa la prevalencia de la norma de

22 DOLINGER, Jacob. direito Internacional privado: parte geral. 7. ed. Rio de Janeiro: Renovar, 2003. p. 405.

${ }^{23}$ Ibidem, p. 408-409. 
un derecho de integración sobre cualquier otra ley nacional en sentido lato, que pudiere ser correctamente tipificada como de orden público en cualquiera de sus dos modalidades.

Iniciamos con esa frase para destacar, primero la actualidad del tema, $\mathrm{y}$, segundo, para demostrar que el orden público regional del Mercosur ya es evocado en las decisiones jurisdiccionales, en este caso, en el Tribunal Permanente de Revisión del Mercosur - TPR, en sede de opinión consultiva emitida en 03/04/2007.

Pero realmente existe un orden público regional? Creemos que si, pero es necesario darle una forma para mejor compréndelo. Bueno, intentemos.

El orden público mercosureño es distinto del orden público nacional, que vimos anteriormente, que cada Estado posee.

El orden público mercosureño es integrado por los principios generales del sistema de integración del cono sur. Claro, aquí dejamos nuestra posición en el sentido de que no es posible dogmatizar el orden público, mucho menos, hacer un listado de normas o principios que lo compone. Pero donde encontrar los principios generales del Derecho de la integración del Mercosur? Donde encontrar los valores del Mercosur?

La búsqueda podría empezar en la propia Teoría General del Derecho de la Integración, con su origen en la experiencia europea. En ese punto encontramos inúmeros principios generales de Derecho Comunitario, por ejemplo, principio de igualdad, cooperación, solidaridad y libertad. ${ }^{24}$ Estés principios, sin duda, conforman parte del orden público mercosureño, una vez que son el proprio eje que sustenta la integración. Otra mirada seria sobre el acervo normativo del bloque, de inicio, en los Tratados fundacionales del mismo, como por ejemplo, el artículo primero del Tratado de Asunción, donde encontramos el principio de la libertad, no discriminación, coordinación, entre otros.

Como todo sistema de derecho occidental, los principios pueden ser encontrados en la jurisprudencia, en nuestro caso, en los laudos de los Tribunales Arbitrales y del Tribunal Permanente de Revisión, en las opiniones consultivas de ese último, bien como, en los fallos de los órganos jurisdiccionales nacionales de los Estados miembros del bloque. ${ }^{25}$

Ahora bien, que los principios generales del derecho de integración hacen parte del orden público del Mercosur, de eso no hay duda, pero un problema que se plantea es si los principios comunes provenientes de los distintos ordenes públicos nacionales de los Estados partes son integrantes de esa esfera regional?

\footnotetext{
24 Algunos de los principios por los cuales entiende la jurista Dreyzin de Klor conformaren parte del orden público del Mercosur. KLOR, Adriana Dreyzin de. El orden público subregional. Revista de Derecho Privado y Comunitario, Buenos Aires, v. 12, 1996.

${ }^{25}$ En ese sentido, vale destacar las publicaciones de la obra: Informe sobre la Aplicación del Derecho del Mercosur por los Tribunales Nacionales, editada por la Secretaria del Mercosur.
} 
Para ese autor, diferente de otros distinguidos juristas ${ }^{26}$, el orden público regional encontrase en otro nivel, distinto del nivel del orden público nacional. Todavía el autor es un principiante y resulta difícil defender que parte del orden público regional proviene de una sumatoria de los distintos órdenes públicos nacionales, cuando encuentran principios comunes. Si bien es cierto que hay una conexión entre el orden público regional y los órdenes públicos nacionales, ese vínculo parece ser aparente, pues como los operadores jurídicos en el caso son generalmente los mismos, la base jurídica-cultural, o sea, los valores, suelen ser los mismos, pero eso no significa que uno está contenido en el otro. Las distinciones están en que las orígenes y los objetivos de los sistemas jurídicos (nacional y de integración) son distintos, el ámbito de aplicación y los efectos irradiados son otros completamente diversos, resultando incomprensible la mezcla entre ellos. Por otro lado, eso no resulta que los valores del orden público nacional sean distintos del orden público regional, no, por lo contrario, generalmente encuentran una base común muy fuerte y sólida, pero hay que llevar en consideración que el contexto de generación y aplicación del valor será distinto.

Por ejemplo, se puede afirmar que el respeto al régimen democrático es un valor, un principio base en el orden público nacional de todos los Estados miembros del Mercosur, pero también podremos decir que es una valor fundamental en el orden público regional. La distinción está en la fuente generadora, en él ámbito de aplicación y en los efectos que puede producir.

Empero cuando hay un conflicto entre el orden público regional y el orden público nacional, cuál es la solución? Un autor entusiasta de la integración mercosureña diría que prevalecen los valores regionales sobre el orden público nacional. Un hermenéutico pos-positivista afirmaría que depende del caso concreto y de la interpretación que da a los hechos y a la norma.

El TPR ya dijo algo sobre el tema al afirmar que:

Es precisamente ese orden público regional, el custodio y la garantía de la imperatividad de cualquier norma del Derecho de Integración, y en consecuencia este concepto de orden público regional debe prevalecer como regla general por sobre cualquier otro concepto de orden público, dentro del espacio de integración en cuestión. Además, en el marco de un proceso de integración el orden público nacional deberá ser interpretado teniendo en cuenta el orden público regional que cabe a este TPR interpretar, de esta manera el orden público nacional resulta enriquecido por el orden público regional, consecuencia de la participación del estado en una comunidad de derecho de orden regional. ${ }^{27}$

${ }^{26}$ KLOR, Adriana Dreyzin de. El orden público subregional. Revista de Derecho Privado y Comunitario, Buenos Aires, v. 12, 1996.

27 MERCOSUR. Tribunal Permanente de Revison. Opinión Consultiva, Asunción, n. 1, 3 abr. 2007. 
No compactamos con esa asertiva del TPR, una vez que no estamos en un sistema completamente supranacional en el marco del Mercosur, o sea, nos encontramos en un sistema intergubernamental. Todavía, es un poco alejo hablar en superposición incondicional de valores regionales sobre valores o principios nacionales, sin antes hablar en delegación de soberanía y voluntad de construir un proceso de integración más profundo y supranacional de hecho.

Intentamos hacer un breve introito sobre orden público regional, pero igualmente para profundizar el tema del orden público, es interesante verificar como se contextualiza la aplicación del orden público en tiempos de vientos pos-positivista y de ruina de la soberanía nacional.

\section{La necesidad de concretizar el orden público}

El orden público no es utilizado por los Estados, por los operadores jurídicos, sin una razón. La aplicación del orden público está estrictamente vinculada por la repulsa de un derecho extranjero, cuando este encuentra como obstáculo los valores de la sociedad de un Estado. Pero como aplicarlo, sin tener una definición exacta? Como aplicarlo teniendo que extraer del seno de la sociedad algo tan subjetivo. El juez en ese caso se ve delante de un cardumen de posibles respuestas que suela difícil decidir.

Y si cambiamos para la órbita regional. Es cierto que los valores democráticos son defendidos por todos los Estados miembros del Mercosur. Pero, cuáles son los contenidos de los valores de la democracia en el Mercosur? Será que elecciones indefinidas es considerado una característica aceptable de democracia para todos los países del Mercosur?

Vemos lo cuanto es difícil conceptualizar abstractamente los valores de una sociedad, por eso entendemos que la abstracción del concepto es imposible, debiendo ser analizada en cada caso concreto.

Para tanto, creemos que resulta interesante la utilización de la teoría de la concreción de la norma del jurista alemán Friedrich Müller, en casos de interpretación y aplicación del orden público.

Para entender la importancia de la aplicación de la metódica normativoestruturante de Friedrich Müller en la interpretación/aplicación del orden público, en nuestro caso del Mercosur, es necesario explicitar las bases en que esa metódica asienta, es decir, el procedimiento de concreción de las normas.

Esa metódica busca delimitar criterios de contraste de la norma, extrapolando los límites de la "representação mental positivista", en especial en el campo del Derecho 
público y derecho constitucional, una vez que "diante de normas jurídicas com âmbitos de normas mais complexos e integral ou parcialmente não-gerados pelo direito, bem como sobretudo diante das prescrições constitucionais, essa representação praticamente não é documentável". ${ }^{28}$

La tarea de concreción de una norma de ámbito regional es por de más compleja cuando comparamos con las restrictas posibilidades de interpretación de una norma penal o civil nacional. En ese sentido, para MÜLLER la concreción de una norma constitucional, en nuestro caso una norma del conjunto de tratados fundacionales, sobrepasa los límites tradicionales de método e interpretación. No se trata aquí, de descartar los métodos clásicos, pero de añadirles otros criterios normativos de contraste de las decisiones, además de la sostenibilidad y posibles efectos de esos métodos sobre la situación concreta.

Es necesario esclarecer lo que sería normatividade, ámbito de la norma y texto de la norma, los tres puntos básico diferenciadores de la teoría de MÜLLER, veamos:

Entre dois aspectos principais o teor literal de uma prescrição juspositiva é apenas a 'ponta do iceberg'. Por um lado, o teor literal serve via de regra à formulação do programa da norma, ao passo que o âmbito da norma normalmente é apenas sugerido como um elemento co-constitutivo da prescrição. Por outro lado a normatividade, pertencente à norma segundo o entendimento veiculado pela tradição, não é produzida por esse mesmo texto. Muito pelo contrário, ela resulta dos dados extralingüísticos de tipo estatal-social: de um funcionamento efetivo, de um reconhecimento efetivo e de uma atualidade efetiva desse ordenamento constitucional para motivações empíricas na sua área; portanto, de dados que mesmo se quiséssemos nem poderiam ser fixados no texto da norma no sentido da garantia de sua pertinência. ${ }^{29}$

En el entender de MÜLLER, la normatividade que se manifiesta por medio de las decisiones prácticas no está necesariamente sólo orientada por el texto de la norma, ya que esta última sólo indica los límites y las posibilidades de la concreción del derecho en el caso concreto. ${ }^{30}$

Resumidamente, el tenor literal de la norma manifiesta lo que MÜLLER denomina de programa de la norma, es decir, la interpretación de dados lingüisticos ${ }^{31}$, que caracterizan el

${ }^{28}$ MÜLLER, Friedrich. Metódos de trabalho do direito constitucional. São Paulo: Max Limonad, 2000. p. 45. En otra oportunidad, Müller resalta: “Assim se evidenciou que o positivismo legalista ainda não superado pela teoria e práxis refletidas, com a sua compreensão do direito como sistema sem lacunas, da decisão como uma subsunção estritamente lógica, e com a sua eliminação de todos os elementos da ordem social não-reproduzidos no texto da norma é tributário de uma ficção que não pode ser mantida na prática." Ibidem, p. 48.

${ }^{29}$ MÜLLER, Friedrich. Metódos de trabalho do direito constitucional. São Paulo: Max Limonad, 2000. p. 53-54.

${ }^{30}$ Ibidem, p. 56.

${ }^{31}$ MAGALHÃES, Marco Túlio Reis. Hermenêutica constitucional: comparação das teorias de Konrad Hesse e Friedrich Müller. Revista Jurídica da Presidência da República, Brasília, v. 7, n. 75, out./ nov.2005. Disponible em: <http://www. planalto.gov.br> . Acesso em: 30 ago. 2007. 
texto de la norma en sí, desfalcado de elementos normativos y empíricos. A nivel jerárquico igual, el ámbito de la norma para MÜLLER consiste en el "recorte da realidade social na sua estrutura básica, que o programa da norma 'escolheu' para si ou em parte criou para si como seu âmbito de regulamentação”.

Vale mencionar que no podemos separar programa de la norma y ámbito de la norma, como etapas de concreción autonómicas. Esto no ocurre, porque el ámbito de la norma, no se restringe a un conjunto de hechos sociales o valorativos que se encuentran espacialmente desconectados del programa de la norma, por lo contrario, la esencia de la normatividade está en el hecho de que el ámbito material forma parte integrante de la prescripción jurídica, ya que "o programa da norma destaca o âmbito da norma como componente da hipótese legal normativa"32. . Concluyendo, el ámbito de la norma es la conexión creada entre los posibles resultados en realidad social según el panorama selectivo y valorativo del programa de la norma.

El proceso de concreción como metódica estruturante tiene por objetivo analizar cuestiones concretas e interpretarlas según las posibilidades reales de interpretación de aquel caso, teniendo como paradigma la prescripción jurídica. Para tanto, MÜLLER resalta algunos elementos integrantes de esa concreción, dividiéndolos en dos grupos, siendo el primero de ellos, los elementos referentes al tratamiento del texto de la norma, y el segundo, aquellos que dicen respeto la interpretación de textos normativos, es decir, el análisis del ámbito de la norma.

Varios son los elementos de concreción de la norma, el primer grupo son los elementos metodológicos strictiore sensu, que comprenden la configuración de la interpretación gramatical, histórica, genética, sistemática y teleológica, además de los principios de interpretación de la constitución (del derecho de integración), tales como, el imperativo de la interpretación conforme la constitución (los tratados fundacionales), praticabilidade, interpretación a partir del nexo de la historia de las ideas, efecto integrador, unidad de la constitución (del derecho de integración originario), cuadro global de derecho pre-constitucional (pre-integración), concordancia práctica, fuerza normativa de la constitución (de los tratados fundacionales), y sobre todo, a partir de la axiomatización en el derecho constitucional (del derecho de integración).

El segundo grupo, es decir, los elementos de la concreción a partir del ámbito de la norma y del ámbito del caso son elementos que auxiliarán en la fundamentación de la decisión, mediante exposiciones más detalladas del caso en cuestión. Además de eso, no hay como negar la necesidad de una conexión más estrecha con la sociología, la ciencia política, la economía y otros campos de la ciencia, cuando del análisis de un caso jurídico. Los dados empíricos adquiridos en esas ciencias auxilian el jurista en el que podremos llamar de "investigación de

${ }^{32}$ MÜLLER, Friedrich. Metódos de trabalho do direito constitucional. São Paulo: Max Limonad, 2000. p. 58. 
los hechos de derecho", y tiene fundamental importancia para el análisis estructural del ámbito de la norma de lege ferenda (política de derecho y de la legislación) y de lege fecha (concreción del derecho). ${ }^{33}$

MÜLLER trae todavía otros grupos de elementos de concreción. El tercer grupo trata de los elementos dogmáticos, cuáles sean, la jurisprudencia y la doctrina, resaltando el autor que las técnicas de comunicación están obteniendo en el universo jurídico, sobre todo por medio de esta dogmática jurídica. ${ }^{34}$ Como elementos auxiliares a la concreción de la norma, el autor trae los elementos de técnica de solución, teoría y política constitucional.

En ese sentido, la teoría de Müller parece nos aporta la mejor metódica científica jurídica para el caso, trayendo toda la subjetividad necesaria pero sin perder el límite que debe haber en la interpretación y aplicación del orden público a un caso concreto.

\section{Conclusiones}

La idea de ese artículo fue de traer aportes de distintas visiones del mundo jurídico. Desde del derecho internacional privado, buscamos el objeto de la investigación: el orden público. Sobre ese último transcurrimos el histórico, las características, los distintos niveles y su operatividad. En la mayor parte de las veces, desde una formación jurídica doctrinaria brasileña.

Bajo la perspectiva del derecho de la integración, tiramos preguntas, dudas, inquietudes sobre la existencia y distinción de un orden público mercosureño en contraposición a un orden público nacional.

Y por último, aportamos la teoría hermenéutica del profesor Müller ya consolidada en el ámbito del derecho constitucional y la trasladamos para nuestro tema en debate.

Las conclusiones que se pueden indiciar son cuatro, muy sencillas, en virtud de esa primera aproximación con el tema, pero un tanto curiosas, como para hacer ese autor continuar su investigación.

a. El orden público nacional y el orden público regional comparten valores comunes en gran parte, pero lo primero no es parte del último, ni si confunden. Sus orígenes, ámbitos de aplicación y efectos ocurren en niveles distintos.

b. El orden público regional no está por arriba del orden público nacional, ellos conviven en coordinación, una vez que el Mercosur no encontrase en un sistema supranacional completo, al contrario, el derecho del Mercosur es fruto de un sistema intergovernamental de decisiones.

\footnotetext{
${ }^{33}$ Ibidem, p. 90.

${ }^{34}$ MÜLLER, Friedrich. Metódos de trabalho do direito constitucional. São Paulo: Max Limonad, 2000. p. 92.
} 
c. En el momento de interpretar el derecho de la integración, bien como, concretizar el orden público, debe ser utilizado, además de los principios de interpretación clásicos, los principios de interpretación del derecho de la integración, tales como, el imperativo de la interpretación conforme los tratados fundacionales, praticabilidade, interpretación a partir del nexo de la historia de las ideas, efecto integrador, unidad del derecho de integración originario, cuadro global de derecho pre-integración, concordancia práctica, fuerza normativa de los tratados fundacionales, y sobre todo, a partir de la axiomatización en el derecho de la integración. Además de siempre llevar en consideración la doctrina y la jurisprudencia sobre el tema del caso en cuestión.

c. Cuando del análisis de un caso jurídico que involucre el derecho de la integración o/y el orden público mercosureño, la necesidad de una conexión interdisciplinar con la sociología, la ciencia política, la economía, las relaciones internacionales y otros campos de la ciencia, en un campo como la integración regional que es tan amplio y demanda esa necesariamente esa amistad.

\section{Mercosur's public policy: an introduction}

\section{Abstract}

This article's objective is to instigate a debate in the field of private international law of integration on an original theme: the existence of a regional public policy. The text goes trough the history, characteristics, different standards and operation of public order, especially from the doctrinal bases of the great master Dolinger. From the perspective of the integration law it is presented the concern about the existence of a distinction between a mercosur's public policy and a national public policy. In the end, the theory of Professor Friedrich Müller, now consolidated under the constitutional law and transferred to our theme for discussion is presented as a source to reach some conclusions about the coexistence of the national public order and regional public policy.

\section{Referências}

DOLINGER, Jacob. Direito internacional privado: parte geral. 7. ed. Rio de Janeiro: Renovar, 2003.

ETIENNE BARTIN, Principles de droit international privé. [S.l.: s.n.]. 
GOLDSCHMIDT, Werner. Derecho internacional privado. 9. ed. Buenos Aires: Depalma, 2002.

KLOR, Adriana Dreyzin de. El orden público subregional. Revista de Derecho Privado y Comunitario. Buenos Aires, v. 12, 1996.

MAGALHÃES, Marco Túlio Reis. Hermenêutica constitucional: comparação das teorias de Konrad Hesse e Friedrich Müller. Revista Jurídica da Presidência da República, Brasília, v. 7, n. 75, out./nov. 2005. Disponible em: <http://www.planalto. gov.br> . Acesso em: 30 ago. 2007.

MERCOSUR. Tribunal Permanente de Revision. Opinión Consultiva Asunción, n. 1, 3 abr. 2007.

MÜLLER, Friedrich. Metódos de trabalho do direito constitucional. São Paulo: Max Limonad, 2000 . 